\title{
GPPS-BJ-2019-0217
}

\section{DEVELOPMENT OF A FLIGHT MISSION MODEL AND ITS APPLICATION IN ORDER TO ILLUSTRATE THE INFLUENCE OF VARIABLE THRUST NOZZLES}

\author{
Tim Sauer \\ Chair for Aero Engines \\ Institute of Aeronautics and Astronautics \\ Technische Universität Berlin \\ Tim.Sauer@ill.tu-berlin.de \\ Berlin, Germany
}

\author{
Tim Rückel \\ Chair for Aero Engines \\ Institute of Aeronautics and Astronautics \\ Technische Universität Berlin \\ timrueckel@gmail.com \\ Berlin, Germany
}

\author{
Dieter Peitsch \\ Chair for Aero Engines \\ Institute of Aeronautics and Astronautics \\ Technische Universität Berlin \\ Dieter.Peitsch@ilr.tu-berlin.de \\ Berlin, Germany
}

\begin{abstract}
Future engines tend to have increasingly higher bypass ratios in order to reduce fuel consumption. This goes along with a decrease of the fan pressure ratio which may result in an unchoked nozzle. Thus the fan working line drops whereby the efficiency of the fan can be reduced. To avoid this effect variable area thrust nozzles can be utilized.

For the evaluation of the potentials of variable thrust nozzles with regard to effects on the overall system, a flight mission model of a representative narrow body aircraft is developed based on published data. On the basis of the equations of motion of each individual flight phase, the mission fuel consumption is calculated. A validation of the nominal case on the basis of EUROCONTROL data confirms the accuracy of the results. The nominal case is opposed by an engine with a variable thrust nozzle, which fixes the working line of the fan to the peak efficiency line.

It is shown that the fuel savings per flight hour are most relevant on short-haul flights. This is explained by the relatively high proportion of operating points in the part load range, i.e. those points which deviate significantly from the respective peak efficiency point. Furthermore, it is shown that the potential savings of variable thrust nozzles are reduced with increasing bypass ratio, since the reference efficiency increases as well. So the application of such a nozzle modification in future engines can indeed help to stabilize the fan's working line, but not necessarily to operate the aircraft more cost-efficiently.
\end{abstract}

\section{INTRODUCTION AND OBJECTIVE}

Since the trend towards higher bypass ratios (BPR) is unbroken or has even increased due to the rise of the geared turbo fan, the fan gets a more and more important role in the economic efficiency of the engine. If the specific fuel consumption (SFC) is expressed as a function of the fan pressure ratio (FPR) and the BPR, the relation shown in Figure 1 is obtained. An increase of the BPR is not only accompanied by a reduction of the best possible SFC but also by a reduction of the optimal FPR. This leads commonly to an unchoked bypass nozzle respectively to a low fan working line, especially in the part load range or at low flight Mach numbers. This in turn leads to an offset between the actual operating point at part load and the peak efficiency point at given thrust.

A concept, which aims to address this issue, is the variable area thrust nozzle. By adapting the nozzle exit area, the mass flow rate of the fan is adjusted, allowing the fan to operate at a higher level of efficiency.

The relevance of a nozzle adjustment for the overall system was already emphasized in (Smith, 1995). However, only a binary adjustment option was examined here on the basis of two exemplary flight missions. Furthermore, the variable thrust nozzle was the subject of numerous studies on noise minimization of aircraft engines (Hall \& Crichton, 2005); (de la Rosa Blanco, Hall, \& Crichton, 2007); (Hall \& Crichton, Engine Design Studies for a Silent Aircraft, 2007); 
(Crichton, Xu, \& Hall, 2007). The impact on performance is assessed here only to a limited extent.

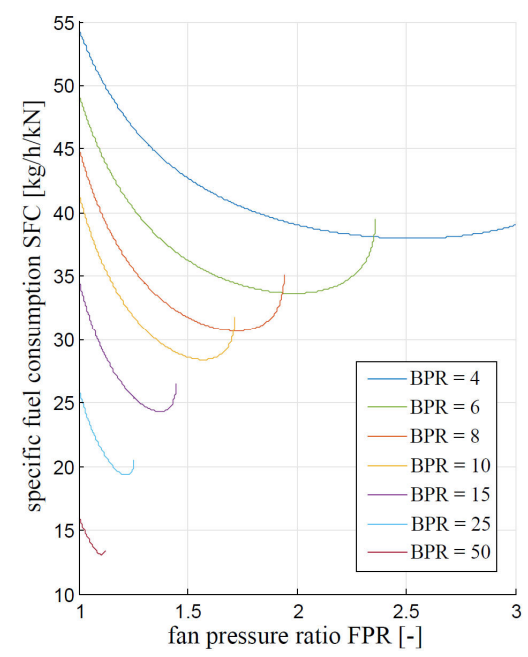

Figure 1 Effects of bypass ratio BPR on fan pressure ratio FPR and specific fuel consumption SFC

There are various approaches for the implementation of a variable nozzle outlet geometry. In (Chaudhry, 2014), an implementation is presented on the basis of a cable actuator system. In (Dittmann \& McCracken, 2013), a linked ring petal actuation is introduced. An actuator approach with shape memory alloy cables and dampers is presented in (Arnold \& Penney, 2008).

This paper examines the potential of a continuously adjustable variable thrust nozzle in the overall system context on the basis of a universal flight mission generator. For this purpose, a mission model implemented with the MatlabSimulink framework is developed, which determines flights of a representative narrow body aircraft as 2D trajectories. Essential mission describing parameters are varied so that the worthwhile range of use of variable thrust nozzles can be described.

\section{METHODOLOGY}

The mission model is used to determine the amount of fuel that can be saved by a variable nozzle as a function of the flight profile. The flight profile can be described by the following segments:

1) Take-off ground run

2) Take-off

3) Climb

4) Cruise

5) Descent

6) Approach and landing

7) Landing ground run

8) Taxiing

Each segment is represented by a sub model, which is simulated one after the other. State variables such as aircraft mass, speed, altitude and range are passed from one model to the next. Depending on the segment, the models use equations of motion which describe either the behavior of the aircraft when it is airborne or when it is in ground contact. Engine data, aircraft data and atmospheric conditions are integrated via lookup tables and are therefore exchangeable.

\section{Engine model}

The utilized engine is described as a synthesis model set up with the performance code GTlab-Performance developed by the German Aerospace Center DLR (Becker, Wolters, Nauroz, \& Otten, 2011). The schematic representation for this generic two shaft, booster charged turbofan engine is given in Figure 2.

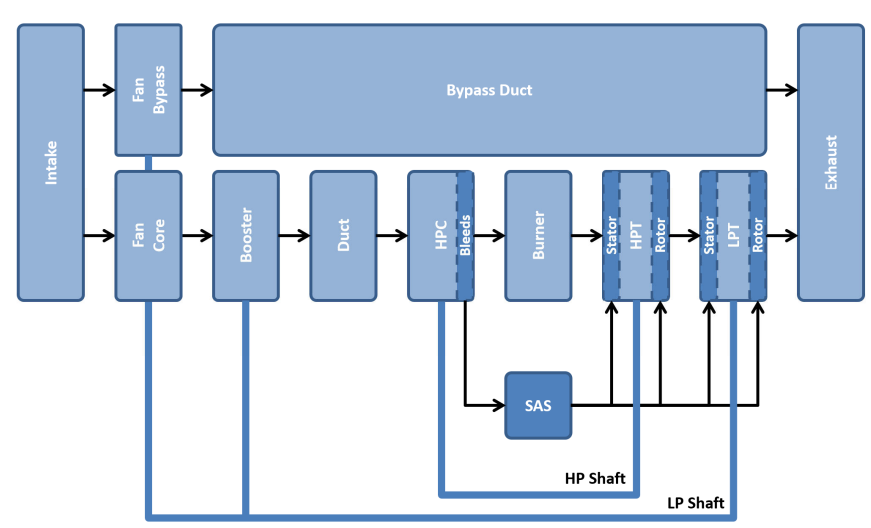

Figure 2 Synthesis model of the simulated engine

The fan is split into two modules. One that processes the mass flow for the core engine and one that represents the bypass region. This ensures that a nozzle adjustment influences the bypass part of the fan directly. The core part of the fan is only influenced in an indirect way via the component interactions. In the remainder of this work, references to the fan represent the fan bypass module only.

The design point data of the synthesis model are based on the take-off information of a representative engine published in (Gunston, 2002) and (Rick, 2013) and summarized in Table 1. The off-design behavior is derived from characteristics recorded in (Kurzke, 2004). The examined characteristic of the fan is derived by (Cornell, 1975). It is scaled to match the engine synthesis model design point.

Table 1 Design point data of utilized engine for ISA standard day

\begin{tabular}{rc|c} 
net thrust & $F_{N}$ & $133.447 \mathrm{kN}$ \\
\hline bypass ratio & BPR & 4.6 \\
\hline fan pressure ratio & FPR & 1.7 \\
\hline overall pressure ratio & OPR & 31.6 \\
\hline inlet mass flow & $w$ & $389.2 \mathrm{~kg} / \mathrm{s}$
\end{tabular}

For the variable nozzle test case, the nozzle exit area is adjusted to match the fan working line with the peak efficiency line of the characteristic. Figure 3 compares the variable nozzle test case with the fixed nozzle reference case in the utilized fan map exemplary. It is apparent that the working line 
of the fan with a fixed nozzle deviates from the peak efficiency line especially in the part load range. In this range the ram air respectively the pressure build-up by the fan is not sufficient to choke the nozzle. Therefore, the mass flow rate of the fan increases while the pressure ratio decreases to maintain the same thrust. In contrast, the variable nozzle specifically reduces the exit area so that the fan is throttled to the peak efficiency line.

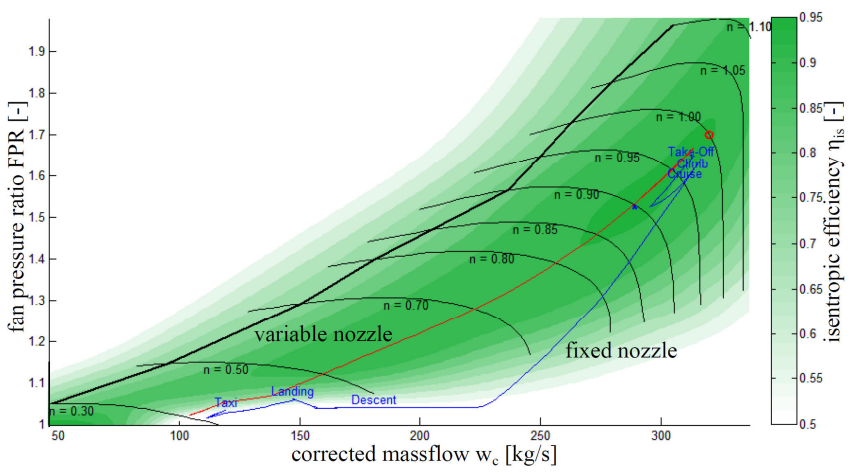

Figure 3 Fan characteristic with working line affected by nozzle

The interface between the mission model and the engine model is implemented via a 4D lookup table. In order to describe a specific operating point of the engine, the flight altitude $h_{0}$, the flight Mach number $M a_{0}$, the delta to ISA temperature $\Delta T_{I S A}$ and the relative speed of the low pressure shaft $N_{L}$ must be known in the mission model. Thus the net thrust $F_{N}$, the fuel flow $w_{F}$, the fan pressure ratio FPR, the corrected mass flow of the fan $w_{c}$ and the isentropic efficiency of the fan $\eta_{i s}$ can be reproduced. Table 2 summarizes the structure of the engine lookup table.

Table 2 Structure of engine lookup table

\begin{tabular}{c|c} 
query parameter & return parameter \\
\hline$h_{0}$ & $F_{N}$ \\
\hline$M a_{0}$ & $w_{F}$ \\
\hline$\Delta T_{I S A}$ & FPR \\
\hline$N_{L}$ & $w_{c}$ \\
\hline & $\eta_{i s}$
\end{tabular}

\section{Aircraft model}

The aircraft model represents a typical narrow body aircraft, which performs a significant part of today's flight volume. The specifications required for the simulation are taken from (AIRBUS S.A.S, 2019) and (Nita \& Scholz, 2012). Based on approximations of the profile drag from (Hull, 2007), a functional relationship between lift coefficient $c_{L}$ and drag coefficient $c_{D}$ can hereby be formulated. Figure 4 illustrates this graphically for the utilized case. The lift to drag curve is dependent on the wing configuration. As soon as the flaps are out, the maximum lift is increased. However, this is accompanied by an increase of drag. The point of the best glide is represented by the point of tangency of the polar with the lift to drag curve. At this point the relation between lift and drag is maximal respectively the thrust required for a stationary flight is minimal. The corresponding glide angle $\mathcal{E}_{\text {Best }}$ is set between the ordinate and the polar.

In addition to the initial aircraft specifications such as maximum take-off mass, cruise Mach number and cruise altitude, the lookup table, which describes the aircraft model, contains the lift to drag characteristics. Thus, $c_{D}$ can be returned to the mission model by specifying $c_{L}$.

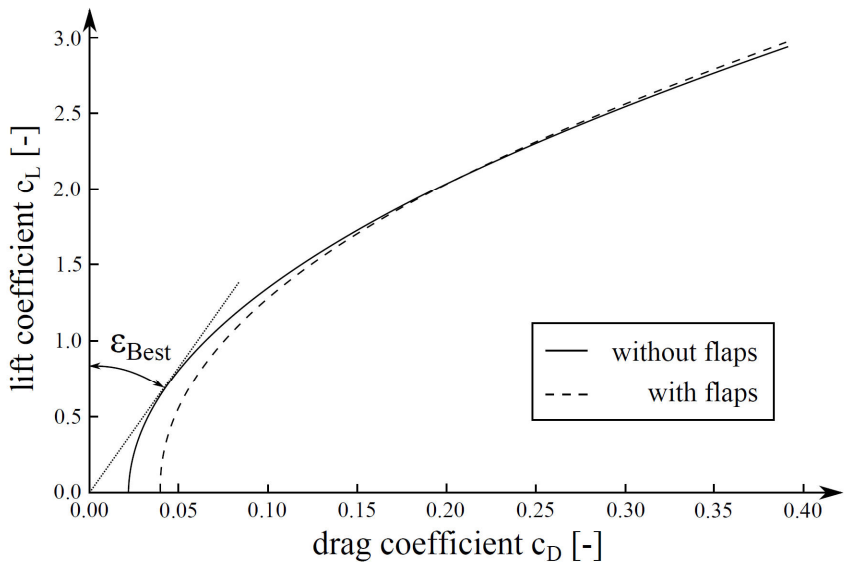

Figure 4 Lift to drag curve of the utilized aircraft

\section{Atmospheric model}

In order to determine the ambient temperature $T_{0}$, the ambient pressure $p_{0}$ and the ambient density $\rho_{0}$ as a function of the flight altitude $h_{0}$, the following approximations according to (Schlichting \& Truckenbrodt, 1967) are applied.

$$
\begin{aligned}
& T_{0}=288.15-6.5 \cdot 10^{-3} \cdot h_{0} \\
& p_{0}=101330 \cdot\left(1-2.256 \cdot 10^{-5} \cdot h_{0}\right)^{5.2559} \\
& \rho_{0}=1.225 \cdot\left(1-2.256 \cdot 10^{-5} \cdot h_{0}\right)^{4.2559}
\end{aligned}
$$

The equations above are valid for the troposphere, i.e. for $h_{0} \in[0 \mathrm{~m} ; 11.000 \mathrm{~m}]$.

\section{Equations of motion}

In order to describe the aircraft movement, a distinction must be made between whether it is airborne or not. So there are two sets of equations of motion describing a 2D trajectory. Both sets correspond to the statements in (Hull, 2007). The following assumptions apply:

- The earth complies with the flat earth model. This means that the earth is approximated as a flat, nonrotating, inertial reference frame. The acceleration of gravity $g$ is constant and perpendicular to the plane.

- The atmosphere does not move relative to the earth. The atmospheric properties depend only on $h_{0}$.

- The aircraft is modeled as a variable mass particle corresponding to the center of gravity $O$. 
- The vector of $F_{N}$ always remains in the flight path, independent of the polar point at which the flight is being performed.

- The flight path angle $\gamma$ is approximated by neglecting the centrifugal force. Thus a phugoid cannot occur.

The corresponding coordinate system is shown in Figure 5. It defined the relation of net thrust $F_{N}$, lift $L, \operatorname{drag} D$ and weight $W$ to the center of gravity $O$ at given altitude $h_{0}$ and distance over ground $x$. As assumed, the flight velocity $v_{0}$ points in the same direction as $F_{N}$. Both deviate by the flight path angle $\gamma$ from the ground.

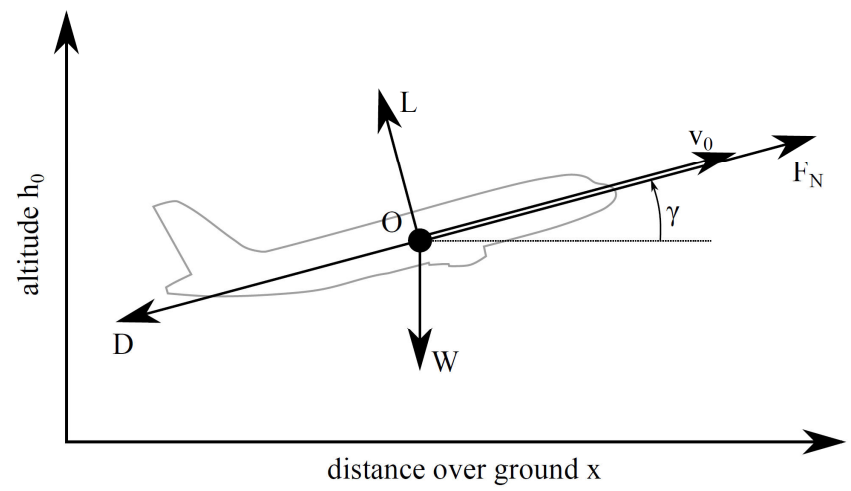

Figure 5 Coordinate system for equations of motion

\section{Motion during flight phases}

The equations of motion (4) to (8) apply to all segments in which the aircraft is airborne.

$$
\begin{aligned}
\dot{x} & =v \cdot \cos (\gamma) \\
\dot{h_{0}} & =v \cdot \sin (\gamma) \\
\dot{v}_{0} & =\left(F_{N}-D-W \cdot \sin (\gamma)\right) \cdot \frac{g}{W} \\
\dot{W} & =w_{F} \cdot g \\
\sin (\gamma) & =\frac{F_{N}}{W}-\frac{D}{L}
\end{aligned}
$$

Lift and drag are defined by the following equations, where $A_{\text {ref }}$ corresponds to the reference area of the wings.

$$
\begin{aligned}
& L=\frac{\rho_{0}}{2} \cdot A_{\text {ref }} \cdot c_{L} \cdot v_{0}{ }^{2} \\
& D=\frac{\rho_{0}}{2} \cdot A_{\text {ref }} \cdot c_{D} \cdot v_{0}{ }^{2}
\end{aligned}
$$

Net thrust and fuel flow are outputs of the engine model, which depends on the operating point within the envelope $\left(h_{0}\right.$, $\left.M a_{0}, \Delta T_{I S A}\right)$ and on the power setting, represented by $N_{L}$. Since the operating point is derived from the previous time step and $c_{D}$ is a function of $c_{L}, N_{L}$ and $c_{L}$ are the only variables that are neither constant nor deducible. They therefore act as control variables for the mission model.

\section{Motion during ground phases}

In the segments take-off ground run, landing ground run and taxiing the aircraft operates on the ground. Here the simplified equations of motion (11) to (14) apply.

$$
\begin{aligned}
\dot{x} & =v \\
\dot{v}_{0} & =\left(F_{N}-D-F_{r}\right) \cdot \frac{g}{W} \\
\dot{W} & =w_{F} \cdot g \\
F_{r} & =(W-L) \cdot \mu_{f}
\end{aligned}
$$

The force $F_{r}$ corresponds to the rolling friction, which depends on the normal force of the aircraft on the ground and the rolling friction coefficient $\mu_{f}$. Corresponding to the motion during flight phases, $N_{L}$ and $c_{L}$ represent the control variables of the model.

\section{Mission segments}

The following sections describe the flight segment models. It is specified how the control variables $N_{L}$ and $c_{L}$ are determined. In addition, the respective exit criteria of the segments are discussed.

\section{Take-off ground run}

At the take-off ground run the aircraft accelerates from standing position to take-off speed. The modified lift to drag relation is applied, which represents the operation with flaps out.

At take-off the engines run at full rated take-off thrust, i.e. $N_{L}=1$. The lift coefficient here is typically in a range between 1.7 and 2.0. In the present study, $c_{L}=1.7$ is assumed for the variable nozzle as well as the static nozzle case. The segment ends as soon as $W-L \leq 0$ applies.

\section{Take-off}

Take-off describes the segment between lift off and reaching the altitude $1.500 \mathrm{ft}$ (Scheiderer, 2008). I.e. the segment end as soon as $h_{0} \geq 457 \mathrm{~m}$ applies. The flaps are still out, so the modified lift to drag relation is valid. The control values are unchanged compared to the take-off ground run.

\section{Climb}

The purpose of climb is to get the aircraft to cruise altitude. Usually, the climb is performed with indicated air speed IAS remaining constant at $300 \mathrm{kt}$ (Scheiderer, 2008). However, since the speed of sound decreases with higher altitude, $M a_{0}$ increases at the same time. Therefore, by reaching the cruise Mach number of $M a_{0}=0.78$ it is kept constant during the further climb.

The engine rating during climb corresponds to $N_{L}=0.92$. The lift coefficient is set via a dynamic inversion control (DI) so that the desired values are realized. The segment ends as soon as the cruising altitude of $h_{0}=11.000 \mathrm{~m}$ is reached or if the descent must be initiated in the case of a short-haul flight. For this purpose, a descent table is used, which connects the current altitude with the required distance to the approach (Scheiderer, 2008). 


\section{Cruise}

The cruise segment is characterized by a constant altitude of $h_{0}=11.000 \mathrm{~m}$ and a constant flight Mach number of $M a_{0}=0.78$. Both specifications are aircraft dependent. During a short-haul flight, the cruise segment may be skipped.

The engine rating is set via a DI control in such a way that the current $N_{L}$ results in a vertical speed of zero. By comparing the Equation (9) with the present weight, $c_{L}$ can be obtained. As soon as the distance specified in the descent table is greater or equal to the remaining distance to the destination, the segment ends.

\section{Descent}

During descent the height is reduced to $1.500 \mathrm{ft}$ above the destination. So the segment ends with $h_{0} \leq 457 \mathrm{~m}$.

For the determination of the power level $N_{L}$ is set by a DI control, so that the thrust is just high enough to overcome the incoming impulse. The lift coefficient is set so that $\varepsilon_{\text {Best }}$ is present.

\section{Approach and landing}

This segment describes the path to the touch down of the aircraft, i.e. until $h_{0}$ corresponds to the pressure altitude of the destination airport. Due to the operation with flaps out the modified relation between lift and drag is used. $N_{L}$ corresponds to the previous segment and $c_{L}$ is set to 2 .

\section{Landing ground run}

During the landing ground run the aircraft is decelerated to taxi speed without the use of a thrust reverser. The segment therefore ends as soon as $v_{0} \leq 9,72 \mathrm{~m} / \mathrm{s}$ applies (Jordan, Ishutkina, \& Reynolds, 2010). $N_{L}$ and $c_{L}$ are derived from the previous segment.

\section{Taxiing}

In this segment, the aircraft rolls over the taxiway at a speed of $v_{0}=9,72 \mathrm{~m} / \mathrm{s}$, e.g. to get to the gate. In order to obtain this required rolling speed, the necessary thrust is determined from Equation (12). $N_{L}$ is set with a DI control in such a way that the required thrust is generated. The lift coefficient is not relevant during taxi. The segment ends after a fixed period of 300 seconds.

\section{RESULTS AND DISCUSSION}

To demonstrate the accuracy of the mission model, data from (EUROCONTROL, 2010) is used. Here, the segments climb, cruise and descent as well as take-off, landing and taxi are summarized. Three published missions with different ranges are simulated for the same jet configuration. The respective relative error of the total fuel consumption is shown in Table 3. The model leads to results with an error of less than $4 \%$. The comparison of the nozzle configurations is thus based on a realistic mission representation.

In the following, the main factors influencing the impact of a variable thrust nozzle are discussed. Unless otherwise stated, an additional mass of $200 \mathrm{~kg}$ per engine for the variable nozzle, a zero-fuel mass of $65.000 \mathrm{~kg}$ for the aircraft and the engine design point data specified in Table 1 are assumed.
Table 3 Comparison of mission model results with published data for nominal case

\begin{tabular}{c|c|c|c}
\multirow{2}{*}{$\begin{array}{c}\text { mission } \\
\text { range }\end{array}$} & \multicolumn{3}{|c}{$\begin{array}{c}\text { relative error of } \\
\text { total fuel consumption }\end{array}$} \\
\cline { 2 - 4 } & $\begin{array}{c}\text { total } \\
\text { mission }\end{array}$ & $\begin{array}{c}\text { climb + cruise } \\
+ \text { descent }\end{array}$ & $\begin{array}{c}\text { take-off + } \\
\text { landing + taxi }\end{array}$ \\
\hline $750 \mathrm{NM}$ & $3.36 \%$ & $3.24 \%$ & $3.94 \%$ \\
\hline $1500 \mathrm{NM}$ & $0.88 \%$ & $0.82 \%$ & $1.36 \%$ \\
\hline $2500 \mathrm{NM}$ & $3.53 \%$ & $3.57 \%$ & $2.96 \%$
\end{tabular}

\section{Dependency on mission range}

A key parameter influencing the economic potential of variable thrust nozzles is the mission range $s$. As Figure 6 shows, although the absolute fuel savings increase with longer flight distances through the use of a variable thrust nozzle, the savings per flight hour are clearly greatest at short distances. This is because the shorter the distance, the higher the relative proportion of flight phases with a lower power setting, i.e. descent and approach. The offset between the operating points of the nominal fan and the fan affected by a variable nozzle is here at its greatest. Therefore, the efficiency potential in these flight segments is particularly high.

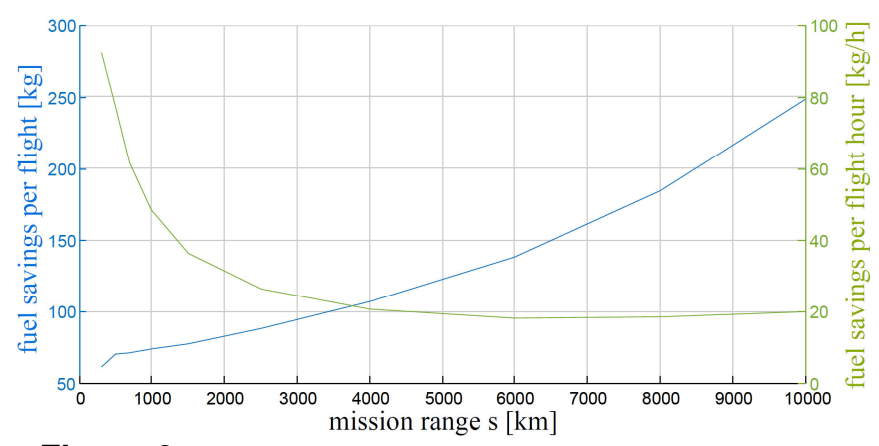

Figure 6 Fuel savings due to a variable thrust nozzle as a function of mission range $s$

Figure 6 also shows that the fuel savings per flight hour increases slightly again with long range applications. It is supposed that the higher take-off mass demands a higher $c_{L}$ during climb and cruise, which leads to greater drag respectively in a larger potential for savings through variable thrust nozzles. However, the savings are still significantly higher for short-haul flights.

\section{Dependency on nozzle mass}

The additional weight of a variable nozzle system results in an increase of the fuel consumption of the flight. This must be put in relation to the savings achieved by the improved determination of operating points. Figure 7 shows the fuel savings achieved by variable nozzles as a function of their mass, both absolute and time-related. Again, the mission range has a huge effect, so it is included here as a further parameter. It can be seen that the additional nozzle mass on long-haul flights can be compensated less strongly. This is due to the fact 
that the cruise segment, which is dominant here in terms of time, has only a small savings potential. An additional mass of more than $1.1 \mathrm{t}$ in total would result in a permanent penalty here, even without considering other additional costs.
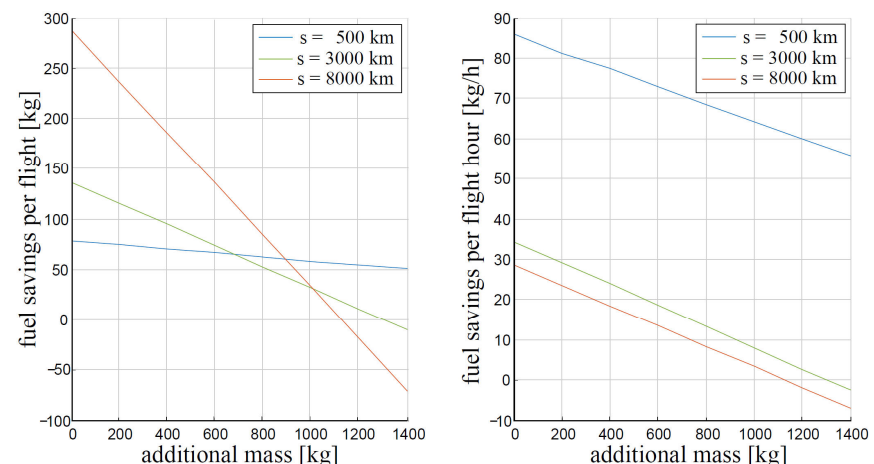

Figure 7 Fuel savings due to variable thrust nozzles as a function of the additional nozzle mass

\section{Dependency on zero-fuel mass}

Another influencing factor that has to be discussed is the zero-fuel mass, which either represents the payload or the aircraft size. As can be seen in Figure 8, there is a fundamental difference between the mass consideration for short- and longhaul applications.
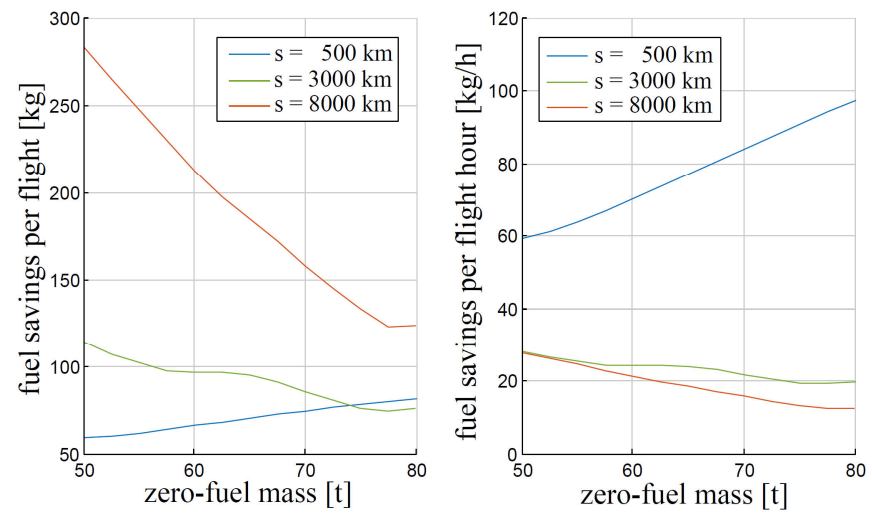

Figure 8 Fuel savings due to variable thrust nozzle as a function of zero-fuel mass

While the savings potential decreases with higher mass on long missions, it increases on short missions. For long flights, the cruise segment is decisive. Here, additional mass leads to an increased thrust requirement. Thus, the operating point of the fan is rather in the full load range and therefore closer to the peak efficiency line. The savings potential is therefore lower. For short-haul flights, the share of the cruise segment is reduced and the climb and descent segments are decisive. While during descent $c_{L}$ is always at its optimum, it is influenced by the aircraft mass during climb. Here, an increased mass requires a higher lift coefficient, which also leads to more drag. This enables the variable thrust nozzle to achieve greater savings potential. This is also the reason why the trend is reversed for long-haul flights with a very high zero-fuel mass, since the relative share of the climb segment rises with increasing mass.

\section{Dependency on BPR}

In order to illustrate the influence of the engine size as well, the dependency on the bypass ratio is examined. With increasing BPR, the amount of mass flow directly affected by a variable thrust nozzle is increased. Nevertheless, the savings potential decreases, as Figure 9 shows. This is due to the fact that SFC also improves with higher BPR, which reduces the absolute fuel savings that can be achieved with a variable thrust nozzle.


Figure 9 Fuel savings due to variable thrust nozzle as a function of the bypass ratio

\section{Consideration of additional costs}

As shown in the previous sections, the application of a variable thrust nozzle leads in almost all cases to a reduction of the fuel consumption. However, this advantage must be put into perspective, since other costs are incurred as a result of the use of such a modification. These costs essentially consist of nozzle specific development, manufacturing and maintenance, which can be allocated as flight hour-related costs. Thus, an operator-dependent threshold can be determined, which defines the range of benefit of a variable thrust nozzle. However, this threshold depends on the fuel price and should therefore be chosen with a certain tolerance.

\section{CONCLUSIONS}

In this paper a mission model is presented, which reproduces the operational spectrum of a representative narrow body aircraft. Worthwhile areas of an engine application with a variable thrust nozzle are identified:

- In particular, short-haul flights of up to about $1500 \mathrm{~km}$ benefit significantly with fuel savings of $35 \mathrm{~kg} / \mathrm{h}$ and more. The reason for this is that here engines spend a significant amount of time in an operating area that has a great potential for improvement.

- Furthermore, twin-engine aircrafts benefit more from the use of variable thrust nozzles than aircrafts with more engines. Since the additional mass of the nozzle modification restricts fuel savings, it should be as low as possible. A lower number of affected engines contributes to this.

- On short-haul flights, aircrafts with a high zero-fuel mass are more likely to achieve a profit. On the other 
hand, light aircrafts have a greater chance to generate profit on long-haul flights. This is due to the relocation of the fan operating points through the variable nozzle in the particular decisive flight segments.

- The savings potential is much more evident for engines with a low BPR. Engines with a high BPR are already so effective that the added value of a variable thrust nozzle competes with the operating costs.

It becomes apparent that the beneficial field of application of variable thrust nozzles is opposed to the current development of aviation. In particular, the trend towards larger bypass ratios continues unabated. Furthermore, the identified operational area of short-haul flights is already covered by turboprop applications or by turbofan engines, which also need to perform medium-haul flights. Consequently, the development and use of variable thrust nozzles on future engines is unlikely to be economical. However, the contribution to a quieter aircraft remains evident as the studies mentioned above have shown.

\section{NOMENCLATURE}

\begin{tabular}{ll}
$A_{r e f}$ & reference area of the wings \\
BPR & bypass ratio \\
$c_{D}$ & drag coefficient \\
$c_{L}$ & lift coefficient \\
$D$ & drag \\
DI & dynamic inversion control \\
$F_{N}$ & net thrust \\
FPR & fan pressure ratio \\
$F_{r}$ & rolling friction \\
$g$ & acceleration of gravity \\
$h_{0}$ & flight altitude \\
IAS & indicated air speed \\
ISA & International standard atmosphere \\
$L$ & lift \\
$M a_{0}$ & flight Mach number \\
$N_{L}$ & relative speed of the low pressure shaft \\
$O$ & centre of gravity \\
OPR & overall pressure ratio \\
$p_{0}$ & ambient pressure \\
$s$ & mission range \\
SFC & specific fuel consumption \\
$T_{0}$ & ambient temperature \\
$v_{0}$ & flight velocity \\
$w$ & inlet mass flow \\
$W$ & weight \\
$w_{c}$ & corrected mass flow \\
$w_{F}$ & fuel flow \\
$x$ & distance over ground \\
$\gamma$ & flight path angle \\
$\Delta T_{I S A}$ & delta temperature to ISA \\
$\mathcal{E}_{B e s t}$ & Glide angle with highest $c_{L} / c_{D}$ \\
$\eta_{i s}$ & isentropic efficiency \\
$\mu_{f}$ & friction coefficient \\
$\rho_{0}$ & ambient density \\
& \\
\hline
\end{tabular}

\section{ACKNOWLEDGEMENT}

The work was founded by the Bundesministerium für Wirtschaft und Energie (BMWi) as per resolution of the German Federal Parliament under grant number 20E1304B, which is highly acknowledged by the authors.

The authors also appreciate the German Aerospace Center DLR for providing the performance code GTlab-Performance.

\section{REFERENCES}

AIRBUS S.A.S, Customer Services, Technical Data Support and Services. (2019). AIRBUS A320. Aircraft Characteristics Airport and Maintenance Planning. Blagnac, France.

Arnold, S. M., \& Penney, N. (2008). Variable area nozzle including a plurality of convexly vanes with a crowned contour, in a vane to vane sealing arrangement and with nonuniform lengths Patentnr. US 7,458,221 B1.

Becker, R. G., Wolters, F., Nauroz, M., \& Otten, T. (2011). Development of a gas turbine performance code and its application to preliminary engine design. 60th German Aerospace Congress (DLRK), Bremen, Germany.

Chaudhry, Z. (2014). Fan variable area nozzle with cable actuactor system. Patent No. US 8,800,260 B2.

Cornell, W. G. (1975). Experimental Quite Engine Program. Washington D.C., USA: NASA CR-2519.

Crichton, D., Xu, L., \& Hall, C. A. (2007). Preliminary Fan Design for a Silent Aircraft. ASME Journal of Turbomachinery. Vol. 129, pp. 184-191.

de la Rosa Blanco, E., Hall, C. A., \& Crichton, D. (2007). Challenges in the Silent Aircraft Engine Design. AIAA 2007454. 45th AIAA Aerospace Sciences Meeting and Exhibit. Reno, Nevada, USA.

Dittmann, R., \& McCracken, R. A. (2013). Linked ring petal actuation for variable area fan nozzle. Patentnr. US 2013/0306755 Al.

EUROCONTROL. (2010). Fuel Burn Estimator for the EU ETS. Task Force on Emission Inventories \& Projections. Larnaca, Cyprus.

Gunston, B. (2002). Jane's Aero-Engines. pp. 181-184. Coulsdon, Surrey, UK: Jane's Information Group.

Hall, C. A., \& Crichton, D. (2005). Engine And Installation Configurations For A Silent Aircraft. ISABE2005-1164. ISABE International Symposium on air breathing engines. Munich, Germany.

Hall, C. A., \& Crichton, D. (2007). Engine Design Studies for a Silent Aircraft. ASME Journal of Turbomachinery. Vol. 129, pp. 479-487.

Hull, D. G. (2007). Fundamentals of Airplane Flight Mechanics. pp. 16 ff., p. 267. Berlin, Heidelberg: SpringerVerlag.

Jordan, R., Ishutkina, M. A., \& Reynolds, T. G. (2010). A Statistical Learning Approach to the Modeling of Aircraft Taxi-Time. Lexington, Massachusetts, USA: MIT Lincoln Laboratory.

Kurzke, J. (2004). Compressor and Turbine Maps for Gas Turbine Performance Computer Programs. Dachau, Germany. 
Nita, M., \& Scholz, D. (2012). Estimating the oswald factor from basic aircraft geometrical parameters. Hochschule für Angewandte Wissenschaften Hamburg.

Rick, H. (2013). Gasturbinen und Flugantriebe. p. 716, p. 904 . Berlin \& Heidelberg: Springer-Verlag.

Scheiderer, J. (2008). Angewandte Flugleistung: Eine Einführung in die operationelle Flugleistung vom Start bis zur Landung. pp. 145 ff., p. 243, p. 319. Berlin Heidelberg: Springer-Verlag.

Schlichting, H., \& Truckenbrodt, E. (1967). Aerodynamik des Flugzeugs. Berlin: Springer-Verlag.

Smith, C. J. (1995). Affordable Nacelle Technologies for Future Turbofans. 95-GT-402. ASME International Gas Turbine and Aeroengine Congress and Exposition. Houston, Texas, USA. 